\title{
Prevalence and Epidemiological Trends in Mortality Due to COVID-19 in Saudi Arabia
}

Dema A. Alissa

Ministry of Health

Wejdan Aburas

University of Hail

Hajar Y. Almudaiheem

Ministry of Health

Zohair Al Aseri

King Saud University

Fahad Alrabiah

King Faisal Specialist Hospital and research Center

Hatoon Ezzat

Ministry of Health

Ashraf A. Moulana

Forensic Medicine Center

Maha M. Alawi

King Abdulaziz Hospital, King Abdulaziz University

Eid Al-mutairy

King Faisal Specialist Hospital and research Center

Tareef Alaama

Ministry of Health

Mohammed S. Alamri

Ministry of Health

Manal S. Bamousa

Ministry of Health

Adel A. Alshehri

Ministry of Health

Mohammed H. Alosaimi

Ministry of Health

Edward Bentz Devol

King Faisal Specialist Hospital and research Center Ahmed H. Al-jedai ( $\sim$ ahaljedai@moh.gov.sa )

Ministry of Health 


\section{Research Article}

Keywords: COVID-19, case fatality rate, Mortality, Prevalence, Epidemiological Trends, Saudi Arabia

Posted Date: July 14th, 2021

DOl: https://doi.org/10.21203/rs.3.rs-605546/v1

License: (c) (i) This work is licensed under a Creative Commons Attribution 4.0 International License. Read Full License 


\section{Prevalence and Epidemiological Trends in Mortality Due to COVID-19 in Saudi Arabia}

Dema A. Alissa ${ }^{1,2}$, Wejdan Aburas ${ }^{3}$, Hajar Y. Almudaiheem ${ }^{1}$, Zohair Al Aseri ${ }^{4,5}$, Fahad Alrabiah ${ }^{6}$, Hatoon Ezzat $^{7,8,9}$, Ashraf A. Moulana ${ }^{10}$, Maha M. Alawi ${ }^{11}$, Eid Al-mutairy ${ }^{6}$, Tareef Alaama ${ }^{1,2}$, Mohammed S. Alamri ${ }^{1}$, Manal S. Bamousa ${ }^{1,12}$, Adel A. Alshehri ${ }^{13}$, Mohammed H. Alosaimi ${ }^{1,14}$, Edward Bentz Devol ${ }^{15}$, Ahmed H. Aljedai $^{1,2}$

${ }^{1}$ Therapeutic Affairs Deputyship, Ministry of Health, Riyadh, Saudi Arabia

${ }^{2}$ Colleges of Medicine and Pharmacy, Al-Faisal University, Riyadh, Saudi Arabia

${ }^{3}$ University of Hail, College of Pharmacy, Hail, Saudi Arabia

${ }^{4}$ Department of Emergency Medicine and Critical Care, King Saud University, Riyadh, Saudi Arabia

${ }^{5}$ Adult Critical Care, Ministry of Health, Riyadh, Saudi Arabia

${ }^{6}$ Department of Medicine, King Faisal Specialist Hospital and research Center, Riyadh, Saudi Arabia

${ }^{7}$ Hematology programs, Ministry of Health, Saudi Arabia

${ }^{8}$ John Hopkins Aramco Healthcare, Dharan, Saudi Arabia

${ }^{9}$ University of British Columbia, Canada

${ }^{10}$ Forensic Medicine Center, Makkah Al Mukarramah

${ }^{11}$ Infection Control \& Environmental Health Unit, King Abdulaziz Hospital, Department of Medical

Microbiology and Parasitology, King Abdulaziz University, Jeddah, Saudi Arabia

${ }^{12}$ Forensic medicine general directorate, Ministry of health, Riyadh, Saudi Arabia

${ }^{13}$ Forensic Medicine Center, Ministry of health, Riyadh, Saudi Arabia

${ }^{14}$ Mortality Affairs, Ministry of Health, Riyadh, Saudi Arabia

${ }^{15}$ Department of Biostatistics, Epidemiology \& Scientific Computing, King Faisal Specialist Hospital and research Center, Riyadh, Saudi Arabia

\section{Corresponding author:}

Ahmed Al-jedai, Pharm.D., M.B.A., BCPS, FCCP, FAST, FCCP, FASHP

Ministry of Health, Riyadh, Saudi Arabia

ahaljedai@moh.gov.sa

\section{Word count: 3112}

\section{Declarations:}

Ethics Approval Statement: This study was performed in accordance with the Declaration of Helsinki and was approved by the central IRB of the Saudi Ministry of Health (log No: 20-168M). Informed consent was not required by the IRB as this was not an interventional study and exempt was granted.

Consent for publication: Approval for publication was granted by the central IRB of the Saudi Ministry of Health

Availability of data and materials: All data and materials are available upon request

Competing interests: The authors of this manuscript have no conflicts of interest or any direct or indirect financial interests.

Funding: This research project was not funded by any commercial or non-commercial organization.

Authors' contributions:

- Dema A. Alissa: The primary investigator, writing proposal, figures, study design, data collection, data analysis, data interpretation, writing manuscript

- Wejdan Aburas: literature search, writing manuscript.

- Hajar Y. Almudaiheem, Zohair Al Asiri, Fahad Alrabiah, Hatoon Ezzat, Ashraf A. Moulana, Maha M. Alawi, Eid Al-mutairy, Tareef Alaama, Mohammed S. Alamri, Manal S. Bamousa, Adel A. Alshehri, Mohammed H. Alosaimi: Reviewing manuscript, reviewing cases and methodology

- Edward Bentz Devol: Data analysis

- Ahmed H. Al-jedai: Study design, data interpretation, and writing manuscript

Acknowledgment: The authors would like to thank Tahani Altamimi, Rawan Almasuood, Fouziah Alharbi, Mohammed Masaad Al-otaibi, Razan Zahran, and Khaulah Alokili for their assistance with collecting data. 


\begin{abstract}
:
Background:

Coronavirus disease of 2019 (COVID-19) created a major public health emergency and an international concern. It is an infectious respiratory illness caused by acute respiratory syndrome coronavirus 2 (SARS-CoV2). The international mortality rates due to COVID-19 reached 2,748,763 on March 24, 2021. We describe the prevalence, case fatality rate, and epidemiological trends of COVID-19 mortality in Saudi Arabia in this paper.
\end{abstract}

\title{
Method:
}

A systematic approach of evaluating COVID-19 related mortalities was established in Saudi Arabia. A scientific committee that evaluated all reported cases with suspicious or confirmed COVID-19 disease using a standardized electronic form. A data registry of all deaths with all clinical parameters was built based on active reporting from all healthcare facilities in Saudi Arabia. Analysis of data using national and regional crude case fatality rate (cCFR) and death per 100,000 population was carried. Descriptive analysis of age, gender, nationality, and comorbidities. Mortality trend was plotted per week and compared to international figures.

\section{Results:}

The total reported number of deaths between March $23^{\text {rd }}$ until April 9, 2021 was 6,737. cCFR was reported as $1.70 \%$, and death per 100,000 population was reported as 19.24 which compared favourably to figures reported by several developed countries. Highest percentages of deaths were among individuals aged between 60-69 years, males (74\%), individuals with diabetes (60\%), and Hypertension (50\%).

\section{Conclusion:}

Case fatality rate and death per 100,000 population in Saudi Arabia is among the lowest in the world due to multiple factors. Several comorbidities have been identified namely diabetes, hypertension, obesity, and cardiac arrhythmias.

\section{Key worlds:}

COVID-19, case fatality rate, Mortality, Prevalence, Epidemiological Trends, Saudi Arabia 


\section{Introduction}

Coronavirus disease of 2019 (COVID-19), an infectious respiratory illness caused by acute respiratory syndrome coronavirus 2 (SARS-CoV-2), has devastating implications on health, economy, and daily life.

The first case of COVID-19 had emerged in Wuhan, China, in late December of 2019. Cases continued to mount around the world, with the first confirmed case announced in Saudi Arabia in early March 2020. ${ }^{(3)}$ COVID-19 was declared as a pandemic by the World Health Organization (WHO) in March of 2020. By mid-April 2021, approximately 135 million confirmed cases with COVID-19 were reported worldwide, with $2,917,830$ thousand related deaths. ${ }^{(1,2)}$

Several risk factors for negative outcomes have been identified. Specific minority ethnic groups are disproportionally affected by severe COVID-19 outcomes. ${ }^{(4)}$ However, whether this is linked to genetic predisposition, socio-economic vulnerabilities, access to care, or other associated factors, have yet to be determined. Regarding gender, it has been well-established that males are at nearly 1.7-fold higher risk of death due to COVID-19 than females. ${ }^{(5)}$ The elderly population is at a higher risk of death ${ }^{(5,6)}$, but this might be attributed to their pre-existing medical conditions such as cardiovascular diseases, diabetes, respiratory diseases, or cancer independently associated with increased risk of death related to COVID-19. ${ }^{(5-7)}$ Obesity has also been shown to contribute to disease severity ${ }^{(8,9)}$.

To properly evaluate the impact of COVID-19 on society, excess deaths have been recognized as an essential and meaningful measure. It was reported as the third leading death in the US right after heart diseases and cancer. ${ }^{(10)}$ It has been suggested that the mortality rate due to COVID-19 could be under or overestimated depending on reporting mechanism and definition of COVID-19 direct cause of mortality. $(7,11)$

Excess mortality estimates the degree to which currently measured mortality exceeds baseline levels estimated using historical data. Rapid mortality surveillance (RMS), "a system that generates daily or weekly counts of total mortality by age, sex, date of death, place of death" was proposed to inform decision-makers about the trajectory and magnitude of the pandemic, with excess mortality being the main focal point. ${ }^{(11)}$ 
The World Health Organization (WHO) defined death due to COVID-19 as "A death resulting from a clinically compatible illness, in a probable or confirmed COVID-19 case, unless there is a clear alternative cause of death that cannot be related to COVID disease (e.g., trauma). ", the death caused by COVID-19 may not be credited to another disease and should be counted freely of prior conditions that are associated with triggering a severe course of COVID-19. ${ }^{(12)}$

Kingdom of Saudi Arabia (KSA) is divided into 13 regions covered by 20 health directorates. Each directorate has its own autonomy in managing its health affairs according to policies and guidelines set by the Ministry of Health (MOH). ${ }^{(13)}$

The study aimed to report prevalence and epidemiological trends of mortality due to COVID-19 disease. We also aimed to quantify the extent to which having comorbidities increases the chance of death from COVID-19.

\section{Methods}

This study was performed in accordance with the Declaration of Helsinki and was approved by the central IRB of the Saudi Ministry of Health (log No: 20-168M). All methods were carried out in accordance with relevant guidelines and regulations of the Kingdome of Saudi Arabia. Informed consent was not required by the IRB as this was not an interventional study and exempt was granted.

Daily death data for the 20 health directorates were studied and obtained from the MOH and non-MOH public and private hospitals from March 23, 2020, through April 9, 2021. The analysis included all direct causes of death due to COVID-19.

According to the WHO definition, the Saudi Ministry of Health registers COVID-19 as a possible cause of death under three categories. First, direct death, in which death resulted from a clinical illness compatible with COVID-19 infection for confirmed or suspected cases. Second, indirect death, death resulted from another disease (e.g., diabetes, cardiovascular diseases, emphysema, etc.), and the patient's condition worsened due to a confirmed or suspected COVID-19. The last scenario is death unrelated to COVID-19, which is any death in a confirmed or suspected case with COVID-19, but COVID-19 was not a direct or indirect cause of death. ${ }^{(3)}$ (Figure 1) 
The COVID-19 mortality scientific committee was established by the Minister of Health to determine the causes of deaths during the COVID-19 pandemic, report COVID-19 mortalities, and evaluate the quality of care provided to patients with COVID-19. The committee meets daily to assess and evaluate each case and decide whether mortality is direct, indirect, or unrelated to COVID-19.

Any mortality case with confirmed or suspected COVID-19 must be reported to the COVID-19 mortality scientific committee using the approved electronic form within 3 hours from the time of death. The form contains all needed information to assess and evaluate the cause of death (demographics, symptoms, comorbidities, co-infections, vital signs and laboratory values, all reported investigations, medications, ventilation setting and requirements, and complications during hospital stay) (supplement 1). Analysis of all reports is sent to the statistics department, whereas only direct COVID-19 related mortalities are announced.

The objective of this report is to describe the prevalence of COVID-19 death in Saudi Arabia, including trends of mortality, risk factors of death, and population estimates for the prevalence of the various comorbidities. Additionally, we report the association between comorbidities and death from COVID-19.

\section{Statistical Analysis:}

National and regional crude case fatality rate (cCFR), defined as the number of mortality cases divided by the number of confirmed COVID-19 cases, and the number of mortality cases per 100,000 population were reported. ${ }^{(14)}$ Descriptive statistics using numbers and percentages were used to describe the categorical variables such as nationality, age, gender, comorbidities, and geographical location of case fatalities. Weekly mortality trends were reported as the number of deaths per time period. The mortality trend was plotted per week and compared to international figures.

Relative and absolute measures of association between comorbidities and death were calculated using odds ratios, attributable risk, and attributable risk percent. Population estimates for the prevalence of the various comorbidities were used to calculate population attributable risk estimates for comorbidities.

Conventionally measures of association were derived from data for which each observation is classified along two dimensions - exposure and outcome, and for each dimension is binary. The exposure is comorbidity (yes or no), and the outcome is death from COVID-19 (yes or no). As this study did not 
include subjects not dying, emphasis was placed on cause-specific death and with death from COVID-19 versus death from another cause as the outcome of interest.

Comorbidities were analyzed individually as well as in combinations (e.g., diabetes and obesity together). Furthermore, the unexposed group was regarded in two different ways. We considered the unexposed to be those with no comorbidity and then investigated the extent to which the comorbidity (or combination of comorbidities) was associated with COVID-19 death versus no comorbidity. The second way to consider the unexposed was as those simply without the comorbidity, but possibly with a variety of other comorbidities. The former type of unexposed definition would reflect the isolated association of the comorbidity, whereas the latter would reflect the association of the comorbidity versus the set of other comorbidities seen in the population. In order to calculate the attributable risk and attributable risk percent associated with comorbidities, the risk of death from COVID-19 for the exposed and unexposed was calculated as follows:

$$
\text { Risk }_{\text {exposed }}=\frac{\text { Number of SARS }-\operatorname{CoV} 2 \text { with the comorbidity dying }}{\text { Total number of SARS - CoV } 2 \text { with the comorbidity }}
$$

and

$$
\text { Risk }_{\text {unexposed }}=\frac{\text { Number of } S A R S-\operatorname{CoV} 2 \text { without the comorbidity dying }}{\text { Number of } S A R S-\operatorname{CoV} 2 \text { without the comorbidity }} .
$$

Given these risk values, then the attributable risk and the attributable risk percent are:

$$
\text { Attributable risk }=\text { Risk }_{\text {exposed }}-\text { Risk }_{\text {unexposed }}
$$

and

$$
\text { Attributable risk percent }=\frac{\text { Risk }_{\text {exposed }}-\text { Risk }_{\text {unexposed }}}{\text { Risk }_{\text {exposed }}} \times 100
$$

Finally, the number needed to harm $(\mathrm{NNH})$, defined as the number of subjects infected with SARS-CoV2 who need to be exposed to comorbidity in order for one subject to die from COVID-19, was calculated as

$$
N N H=\frac{1}{\text { Attributable risk }} \text {. }
$$


Measures of association were calculated together with $95 \%$ confidence intervals. Analyses were carried out using SAS/JMP version 15.0.

\section{Results}

Between March 23, 2020, and April 9, 2021, among the 7,761 subjects were studied, 1,025 had died from causes unrelated to COVID-19, and 6,737 had died from causes directly related to COVID-19 from a total of 395,854 infected patients by COVID-19.

Compared to cCFR with Brazil, China, Germany, Italy, South Korea, and the United States, Saudi Arabia's cCFR was $1.70 \%$. (Figure 2). Among the 20 health directorates in KSA, Taif Province accounted for the highest cCFR (4.85\%), while Qunfotha reported only five deaths during this period with a cCFR of $0.22 \%$ (Table 1).

The national number of deaths per 100,000 population was 19.24 (Table 2), with Makkah province reporting the highest (36.42\%) and Qunfotha reporting the lowest (1.52\%). As of April 9, 2021, the total number of confirmed deaths due to COVID-19 in KSA was 6,737 deaths, with the first reported death was on March 23 in Madinah province. The highest number of reported cases of death were reported in the most populated provinces (Riyadh, Jeddah, Makkah, Madinah, and eastern province) (Figure $3 \& 4$ ). The youngest reported death was a 42-days old boy from Jazan on August 18 who developed Multisystem Inflammatory Syndrome in Children (MIS-C), and the oldest was a male of 113 years of age male in Bisha province. Males accounted for $74 \%$ of total deaths, and the highest percentage of deaths per age group was between the age of $60-69$ years (Figure 5). The most common comorbidities associated with death were diabetes (60\%), hypertension (50\%), chronic renal impairment, and obesity (10\%) (Table 3). The highest number of reported mortalities was reached on week 12, which was then plateaued until week 16 and started to decline thereafter. (Figure 6)

Across the whole cohort of subjects who were analyzed, there were 271 distinct comorbidity profiles. Diabetes (OR: 5.8, CI 4.55 - 7.41) and hypertension (OR: 4.92, CI 3.48 - 6.95) were among the most common comorbidities associated with COVID-19 mortality. The top ten most frequently occurring patterns of comorbidities are listed in table 4. Diabetes, hypertension, arrhythmias (OR: 4.37, CI 0.99 19.2), and obesity (OR: 4.53, CI 3.20 - 6.41) were tope single comorbidity that was associated with COVID-19 mortality (Figure 7). Multiple coexisting comorbidities were compared to those without any 
comorbidity with regards to the risk of death, which showed that diabetes with hypertension and obesity (OR: 56.5, CI 7.90 - 406) in combination ranked as the highest multiple comorbidities associated with COVID-19 mortality, followed by the combination of diabetes with hypertension and heart failure (OR: 33, CI 12.20 - 89.40) than diabetes and heart failure combination (OR: 19.2, CI 4.69 - 78.80) (figure 8). Table 5 shows the attributable risk of death and needed number to be hard as measures of absolute measure of the risk of death for each comorbidity.

\section{Discussion}

This is the first report on the prevalence and epidemiological trends of COVID-19 mortality in Saudi Arabia. Several countries have published the prevalence of mortalities related to COVID-19. The crude case Fatality rate among European countries was the highest in Italy $(3 \%) .{ }^{(15)}$ Italy defines death related to COVID-19 in a broader term due to the lack of clear criteria for COVID-19 deaths. Death is recorded as related to COVID-19 in individuals who tested positive by Real-Time-Polymerase Chain Reaction (RTPCR) for SARS-CoV-2 regardless of pre-existing conditions that might have contributed to their death. ${ }^{(16)}$ In China, the case fatality rate reached $5.1 \%$ of confirmed cases. ${ }^{(5,14)}$ while in the UK, $12,6980(2.91 \%)$ of deaths were recorded as related to COVID-19 ${ }^{(14)}$. The Center for Disease Control and Prevention (CDC) in the United States has reported 573,856 COVID-19 cases in the United States (US). The total fatality rate was estimated to be $1.8 \%{ }^{(15,19)}$ The CDC reported no data on serious pre-existing conditions. Due to missing key patients' characteristics, the fatality rate was estimated as a range having the lower bound estimated by using all cases among age group and upper bound estimated by using only cases with known key characteristics. ${ }^{(19)}$

Saudi Arabia has lower cCFR and deaths per 100,000 compared to many developed countries. This could be due to several factors, including multiple strategies of early preventive measures by the government and early lockdown that took place before the first COVID-19 mortality was reported. Intensive care unit (ICU) bed expansion from 6,360-beds to 10,401-beds (increased by 164\%) during the pandemic period played a significant role in accommodating more critical patients. In addition, early outpatient intervention through the creation of "fever clinics" in primary healthcare centers around the Kingdome. These clinics aimed to treat patients with early symptoms to prevent hospital admissions and decongest emergency departments in hospitals. Finally, MOH developed multiple protocols for COVID-19 that are continuously updated. More than 32 protocols covered different aspects of COVID-19-disease, including but not limited to radiology 
preparedness, guidelines for BLS and ACLS for COVID-19 patients, COVID-19 in pregnancy, ICU admission criteria, Mechanical ventilation, high flow nasal cannula and helmet use in covid-19, and COVID-19 treatment protocol.

The number of cases in Italy has reached 112,861 in early April 2021. ${ }^{(17)}$ In China, the prevalence of COVID-19 between men and women was also nearly the same (51.4\% vs. $48.6 \%)$. However, fatality rate among men was significantly higher than women $(\mathrm{RR}=1.67,95 \% \mathrm{CI}=1.47-1.89, \mathrm{p}<0.001) .{ }^{(5)} \mathrm{In}$ the UK, mortality was also higher in men than women (fully adjusted HR 1.59, 1.53-1.65). ${ }^{(18)}$ This is similar to our findings, as males accounted for more than two-thirds of mortalities. This could be explained by the presence of different social and occupational factors among both genders. Biologicals differences cannot be excluded as well. ${ }^{(20)}$

An increase in age was strongly associated with an increased risk of severe COVID-19 outcomes. In the US, individuals aged $\geq 65$ years accounted for $30 \%$ of the cases, half of the ICU admissions, and $80 \%$ of deaths with the highest case-fatality rate (10.4-27.3\%) in adults aged 85 years or older. ${ }^{(21)}$ In the UK, patients above 80 years of age accounted for 1,131,680 (6.5\%) of total recorded mortalities, and 6,474 $(0.57 \%)$ of mortalities were related to COVID-19. Overall cumulative incidence of death 90 days after study start in patients aged above 80 was found to be rising to $0.67 \%$ and $0.44 \%$ in men and women, respectively aged $\geq 80$ years. ${ }^{(18)}$ In Italy, the case-fatality rate was exceptionally high in individuals aged 80 years or older reaching $20.2 \%{ }^{(17)}$ Patients aged above 80 years old in China ${ }^{(5)}$ accounted for $14.8 \%$ of fatalities. Our study showed that most mortalities occurred in patients aged between 60-69 years old.

Minorities ethnic groups have been especially affected by COVID-19, with an increase in fatality rate in the US and UK than most populations. ${ }^{(22,23)}$ In the Bronx, New York City, an area known to have a high poverty rate compared to the national US average ${ }^{(22)}$, deceased Black patients accounted for $24 \%$ of total deaths $(n=160)$, and Hispanic accounted for $68 \%$. The remaining deaths $(8 \%)$ were for other unspecified ethnicities. However, minimal representation of other ethnicities limited the ability to draw a proper assessment of ethnicity and its relation to severe COVID-19 outcomes in the US. ${ }^{(22)}$ In the UK, ${ }^{(23)}$ registered hospital deaths related to COVID-19 (per 100,000) were the highest in Black Caribbean ethnicity, three times the White British majority. Age has established a crucial role in the severity of COVID-19 outcomes. However, even after adjusting for age and geography, minorities still comprise the majority of deaths related to COVID-19 in the UK, making Black African deaths the highest (3.7 times the 
White British group), followed by Pakistani deaths (2.9 times the White British group) and Bangladeshi deaths at twice the deaths of White British group. ${ }^{(23)}$

Individuals with pre-existing conditions are at an exceptionally high risk of death due to COVID-19. Death from non-respiratory causes had a significant proportional increase in 5 US states with the highest excess deaths related to COVID-19. ${ }^{(7)}$ Deaths in individuals with diabetes are increasing by $96 \%$ and having the most significant increase in New York City by $356 \%$. Heart diseases related deaths increased by $89 \%$ and $398 \%$ in New York City. Other non-respiratory diseases that resulted in deaths were also noted. Alzheimer disease-related deaths increased by $64 \%$, and cerebrovascular diseases by $35 \% .{ }^{(7)}$ Diabetes has also been noted to increase the risk of death in both China and UK patients $(\mathrm{RR}=4.43,95 \% \mathrm{CI}=3.49-5.61, \mathrm{p}<$ 0.001. HbA1c $>=58 \mathrm{mmol} / \mathrm{mol}$ had greatest Hazard Ratio, fully adjusted HR 1.95, 1.83-2.07. respectively). ${ }^{(5,18)}$ our study suggests that diabetes is one of the most important comorbidities associated with COVID-19 mortality. This is particularly concerning knowing that diabetes prevalence in Saudi Arabia is about $20 \%$. China and UK have also established an association of increased risk of severe COVID-19 outcomes with respiratory disease (Excluding asthma in both. $\mathrm{RR}=3.43,95 \% \mathrm{CI}=2.42-4.87, \mathrm{p}<0.001$. Fully adjusted HR 1.63, 1.55-1.71. respectively). ${ }^{(5,18)}$ Severe asthma was associated with the risk of death in Chinese patients (Asthma with Oral Corticosteroid use had greatest HR, fully adjusted HR 1.13, 1.01-1.26). ${ }^{(18)}$ This is similar to our findings as respiratory diseases were three times more likely to result in death due to covid19.

Other pre-existing conditions that increased the risk of death in a patient with COVID-19 in our study included cardiovascular diseases, renal impairment, obesity, thromboembolic disorders, thyroid dysfunction, and neurological disorders. A study from China found cardiovascular disease $(\mathrm{RR}=6.75$, $95 \% \mathrm{CI}=5.40-8.43, \mathrm{p}<0.001)$, and hypertension $(\mathrm{RR}=4.48,95 \% \mathrm{CI}=3.69-5.45, \mathrm{p}<0.001)$ among the most common comorbidities associated with COVID-19 mortality. ${ }^{(5)}$ Another study in the UK showed that obesity was associated with an increased risk of death (BMI >40 fully adjusted HR 1.92, 95\% CI 1.722.13). ${ }^{(18)}$ chronic heart disease (Fully adjusted HR 1.17, 1.12-1.22), liver disease (Fully adjusted HR 1.75, 1.51-2.03), stroke/dementia (Fully adjusted HR 2.16, 2.06-2.27), other neurological diseases (Fully adjusted HR 2.58, 2.38-2.79), reduced kidney function (estimated glomerular filtration rate <30 had the greatest HR, fully adjusted HR 2.52, 2.33-2.72), autoimmune diseases (rheumatoid arthritis, lupus or psoriasis, Fully 
adjusted HR 1.19, 1.11-1.27), and other immunosuppressive conditions (Fully adjusted HR 1.70, 1.342.16), were also associated with increased risk of death. ${ }^{(18)}$

It is important to note that we reported the association of different comorbidities, which does not necessarily mean correlation or causality. Furthermore, two critical assumptions are necessary for the validity of the measures of association in this study. Firstly, it must be assumed that the presence or absence of comorbidity is independent of the likelihood of getting infected by the COVID-19 virus. Secondly, the distribution of the comorbidities among the study subjects who died from unrelated causes matches the distribution of the comorbidities in the population of interest.

\section{Conclusion:}

Case fatality rate and death per 100,000 population in Saudi Arabia is among the lowest in the world due to multiple factors. Several comorbidities have been identified, namely diabetes, hypertension, obesity, and cardiac arrhythmias. Data from this study could be used to help in public health decision-making and preparedness efforts. 


\section{References}

1) COVID-19 situation reports. https://www.who.int/emergencies/diseases/novel- coronavirus2019/situation-reports.

2) WHO. WHO Timeline - COVID-19 2020 [Available from: https://www.who.int/news-room/detail/2704-2020-who-timeline---covid-19.

3) SAUDI MOH. COVID 19 Dashboard: Saudi Arabia 2020 [Available from: https://covid19.moh.gov.sa.

4) The Institute for Fiscal Studies. Are some ethnic groups more vulnerable to COVID-19 than others? Available from: https://www.ifs.org.uk/ inequality/chapter/are-some-ethnic-groups-more-vulnerableto-covid-19-than-others/ (2020).

5) Deng, G., Yin, M., Chen, X. \& Zeng, F. Clinical determinants for fatality of 44,672 patients with COVID-19. Crit. Care 24, (2020).

6) Docherty, A. B. et al. Features of 16,749 hospitalised UK patients with COVID-19 using the ISARIC WHO Clinical Characterisation Protocol. medRxiv (2020) https://doi.org/10.1101/2 020.04.23.20076042.

7) Woolf SH, Chapman DA, Sabo RT, Weinberger DM, Hill L. Excess deaths from COVID-19 and other causes, March-April 2020. JAMA. Published online July 1, 2020. doi:10.1001/jama.2020.11787

8) Simonnet, A. et al. High prevalence of obesity in severe acute respiratory syndrome coronavirus-2 (SARS-CoV-2) requiring invasive mechanical ventilation. Obesity (2020) https://doi.org/10.1002/oby.22831.

9) Lighter, J. et al. Obesity in patients younger than 60 years is a risk factor for Covid-19 hospital admission. Clin. Infect. Dis. https://doi.org/10.1093/cid/ciaa415.

10) Ahmad FB, Anderson RN. The Leading Causes of Death in the US for 2020. JAMA. Published online March 31, 2021. doi:10.1001/jama.2021.5469

11) World Health Organization (WHO). Revealing the toll of COVID-19: A technical package for rapid mortality surveillance and epidemic response. Available from: https://www.who.int/publications/i/item/revealing-the-toll-of-covid-19 (2020)

12) World Health Organization. (2020). Estimating mortality from COVID-19: scientific brief, August 4 2020. World Health Organization. https://apps.who.int/iris/handle/10665/333642. License: CC BYNC-SA 3.0 IGO 
13) Walston S, Al-Harbi Y, Al-Omar B. The changing face of healthcare in Saudi Arabia. Ann Saudi Med. 2008;28(4):243-250. doi:10.5144/0256-4947.2008.243

14) WHO. Estimating mortality from COVID-19. [Available https://www.who.int/newsroom/commentaries/detail/estimating-mortality-from-covid-19]

15) COVID-19 CORONAVIRUS PANDEMIC. [Available https://www.worldometers.info/coronavirus/]

16) Onder G, Rezza G, Brusaferro S. Case-Fatality Rate and Characteristics of Patients Dying in Relation to COVID-19 in Italy [published online ahead of print, 2020 March 23]. JAMA. 2020;10.1001/jama.2020.4683. doi:10.1001/jama.2020.4683

17) Livingston E, Bucher K. Coronavirus disease 2019 (COVID-19) in Italy. JAMA. Published online March 17, 2020. doi:10.1001/jama.2020.4344

18) Williamson, E.J., Walker, A.J., Bhaskaran, K. et al. OpenSAFELY: factors associated with COVID-19 death in 17 million patients.Nature (2020). https://doi.org/10.1038/s41586-020-2521-4

19) CDC COVID-19 Response Team. Severe Outcomes Among Patients with Coronavirus Disease 2019 (COVID-19) - United States, February 12-March 16, 2020. MMWR Morb Mortal Wkly Rep. 2020;69(12):343-346. Published 2020 March 27. doi:10.15585/mmwr.mm6912e2

20) Griffith DM, Sharma G, Holliday CS, Enyia OK, Valliere M, Semlow AR, et al. Men and COVID-19: A Biopsychosocial Approach to Understanding Sex Differences in Mortality and Recommendations for Practice and Policy Interventions. Prev Chronic Dis 2020;17:200247.

DOI: http://dx.doi.org/10.5888/pcd17.200247external icon

21) Chilimuri S, Sun H, Alemam A, et al. Predictors of Mortality in Adults Admitted with COVID-19: Retrospective Cohort Study from New York City. West J Emerg Med. 2020;21(4):779-784. Published 2020 Jul 8. doi:10.5811/westjem.2020.6.47919

22) The Institute for Fiscal Studies. Are some ethnic groups more vulnerable to COVID-19 than others? Available from: https://www.ifs.org.uk/ inequality/chapter/are-some-ethnic-groups-more-vulnerableto-covid-19-than-others/ (2020).

23) United States Census - Bronx County. Available at: https://www.census.gov/quickfacts/bronxcountybronxboroughnewyork. 


\begin{tabular}{|c|c|c|c|}
\hline Table 1: national crud case fatality rate (cCFR) by august 6, 2020 \\
\hline Health Directorates & Total Cases & Total Deaths & \% Total Death of Cases \\
\hline Taif & 5,506 & 267 & 4.85 \\
\hline Al Hassa & 9,533 & 462 & 4.85 \\
\hline Jouf & 1,253 & 52 & 4.15 \\
\hline Jizan & 12,641 & 486 & 3.84 \\
\hline Qurayat & 502 & 18 & 3.59 \\
\hline Jeddah & 38,359 & 1,292 & 3.37 \\
\hline Makkah & 30,834 & 915 & 2.97 \\
\hline Northern & 3,337 & 93 & 2.79 \\
\hline Hafr Albatin & 4,587 & 120 & 2.62 \\
\hline Asir & 23,288 & 439 & 1.89 \\
\hline Qasim & 15,461 & 227 & 1.47 \\
\hline Riyadh & 89,481 & 1,312 & 1.47 \\
\hline Al Baha & 4,867 & 69 & 1.42 \\
\hline Bisha & 4,247 & 53 & 1.25 \\
\hline Najran & 6,982 & 80 & 1.15 \\
\hline Tabuk & 14,018 & 89 & 0.63 \\
\hline Ha'il & 31,493 & 190 & 0.60 \\
\hline Madinah & 38,903 & 230 & 0.59 \\
\hline Eastern & 58,250 & 337 & 0.58 \\
\hline Qunfotha & 2,312 & 5 & 0.22 \\
\hline Total & $\mathbf{3 9 5 , 8 5 4}$ & $\mathbf{6 , 7 3 6}$ & $\mathbf{1 . 7 0}$ \\
\hline & & & \\
\hline
\end{tabular}

Table 2: number of deaths per 100,000 population by august 6,2020

\begin{tabular}{|c|c|c|c|}
\hline $\begin{array}{c}\text { Health } \\
\text { Directorates }\end{array}$ & Population & Total Deaths & $\begin{array}{c}\text { Number of deaths per 100,000 } \\
\text { Population }\end{array}$ \\
\hline Makkah & $2,512,462$ & 915 & 36.42 \\
\hline Al Hassa & $1,305,172$ & 462 & 35.40 \\
\hline Jizan & $1,670,569$ & 486 & 29.09 \\
\hline Jeddah & $5,031,820$ & 1,292 & 25.68 \\
\hline Ha'il & 746,046 & 190 & 25.47 \\
\hline Hafr Albatin & 476,443 & 120 & 25.19 \\
\hline Northern & 390,656 & 93 & 23.81 \\
\hline Asir & $1,940,123$ & 439 & 22.63 \\
\hline Taif & $1,387,686$ & 267 & 19.24 \\
\hline Qasim & $1,520,434$ & 227 & 14.93 \\
\hline Riyadh & $8,872,712$ & 1,312 & 14.79 \\
\hline Jouf & 362,580 & 52 & 14.34 \\
\hline Al Baha & 506,866 & 69 & 13.61 \\
\hline Najran & 621,040 & 80 & 12.88 \\
\hline Bisha & 414,197 & 53 & 12.80 \\
\hline Madinah & $2,291,092$ & 230 & 10.04 \\
\hline Qurayat & 180,430 & 18 & 9.98 \\
\hline Eastern & $3,485,383$ & 337 & 9.67 \\
\hline Tabuk & 968,414 & 89 & 9.19 \\
\hline Qunfotha & 329,289 & 5 & 1.52 \\
\hline Total & $\mathbf{3 5 , 0 1 3 , 4 1 4}$ & $\mathbf{6 , 7 3 6}$ & $\mathbf{1 9 . 2 4}$ \\
\hline & & & \\
\hline
\end{tabular}




\begin{tabular}{|c|c|c|}
\hline \multicolumn{3}{|c|}{$\begin{array}{l}\text { Table 3: demographics and baseline characteristics of deceased } \\
\text { patients }\end{array}$} \\
\hline & Number of Patients & Percentage \\
\hline Male gender & 4,993 & $74 \%$ \\
\hline Saudi Nationality & 3,077 & $46 \%$ \\
\hline Medically Free & 933 & $14 \%$ \\
\hline Age $>=70$ & 1,743 & $26 \%$ \\
\hline \multicolumn{3}{|c|}{ Comorbidities } \\
\hline Diabetic & 4,072 & $60 \%$ \\
\hline Hypertension & 3,336 & $50 \%$ \\
\hline Heart failure & 853 & $13 \%$ \\
\hline Renal impairment & 640 & $10 \%$ \\
\hline Obesity & 701 & $10 \%$ \\
\hline Respiratory disorders & 626 & $9 \%$ \\
\hline Neurological disorder & 342 & $5 \%$ \\
\hline Thromboembolic disorders & 184 & $3 \%$ \\
\hline Arrhythmias & 247 & $4 \%$ \\
\hline Thyroid dysfunction & 209 & $3 \%$ \\
\hline Liver impairment & 66 & $1 \%$ \\
\hline
\end{tabular}

\begin{tabular}{|c|c|}
\hline Comorbidity profile & $\begin{array}{c}\text { Number of } \\
\text { subjects (\%) }\end{array}$ \\
\hline Diabetes/Hypertension & $1233(17.9)$ \\
\hline Diabetes alone & $976(14.2)$ \\
\hline Hypertension alone & $378(5.5)$ \\
\hline Obesity alone & $351(5.1)$ \\
\hline Diabetes/Hypertension/Heart failure & $231(3.4)$ \\
\hline Diabetes/Hypertension/Renal impairment & $169(2.5)$ \\
\hline Others & $122(1.8)$ \\
\hline Respiratory disorder alone & $116(1.7)$ \\
\hline Diabetes/Hypertension/Obesity & $113(1.6)$ \\
\hline Heart failure alone & $98(1.4)$ \\
\hline
\end{tabular}




\begin{tabular}{|c|c|c|c|c|c|}
\hline \multicolumn{6}{|c|}{ Table 5: absolute measures of association } \\
\hline Comorbidity & Exposed risk & $\begin{array}{c}\text { Unexposed } \\
\text { risk }\end{array}$ & $\begin{array}{c}\text { Attributable } \\
\text { risk }\end{array}$ & $\begin{array}{r}\text { Attributable } \\
\text { risk percent }\end{array}$ & NNH \\
\hline Diabetes & 0.9236 & 0.7618 & 0.162 & $18 \%$ & 6.2 \\
\hline Hypertension & 0.9233 & 0.7927 & 0.131 & $14 \%$ & 7.7 \\
\hline Heart failure & 0.9392 & 0.8399 & 0.099 & $11 \%$ & 10.1 \\
\hline $\begin{array}{c}\text { Renal } \\
\text { impairment }\end{array}$ & 0.9212 & 0.8442 & 0.077 & $8 \%$ & 13.0 \\
\hline Obesity & 0.9276 & 0.8415 & 0.086 & $9 \%$ & 11.6 \\
\hline $\begin{array}{l}\text { Respiratory } \\
\text { disorder }\end{array}$ & 0.9133 & 0.8452 & 0.068 & $7 \%$ & 14.7 \\
\hline $\begin{array}{l}\text { Thromboembolic } \\
\text { disorders }\end{array}$ & 0.8933 & 0.8499 & 0.043 & $5 \%$ & 23.0 \\
\hline Arrhythmias & 0.8920 & 0.8497 & 0.042 & $5 \%$ & 23.6 \\
\hline $\begin{array}{c}\text { Thyroid } \\
\text { dysfunction }\end{array}$ & 0.9133 & 0.8492 & 0.064 & $7 \%$ & 15.6 \\
\hline $\begin{array}{c}\text { Neurological } \\
\text { disorder }\end{array}$ & 0.8694 & 0.8501 & 0.019 & $2 \%$ & 51.8 \\
\hline $\begin{array}{c}\text { Liver } \\
\text { impairment }\end{array}$ & 0.7945 & 0.8516 & -0.057 & $-7 \%$ & -17.5 \\
\hline Other & 0.8049 & 0.8519 & -0.047 & $-6 \%$ & -21.3 \\
\hline
\end{tabular}


Figure 1: Cause of Death Flowchart Evaluation by Saudi MOH for COVID-19

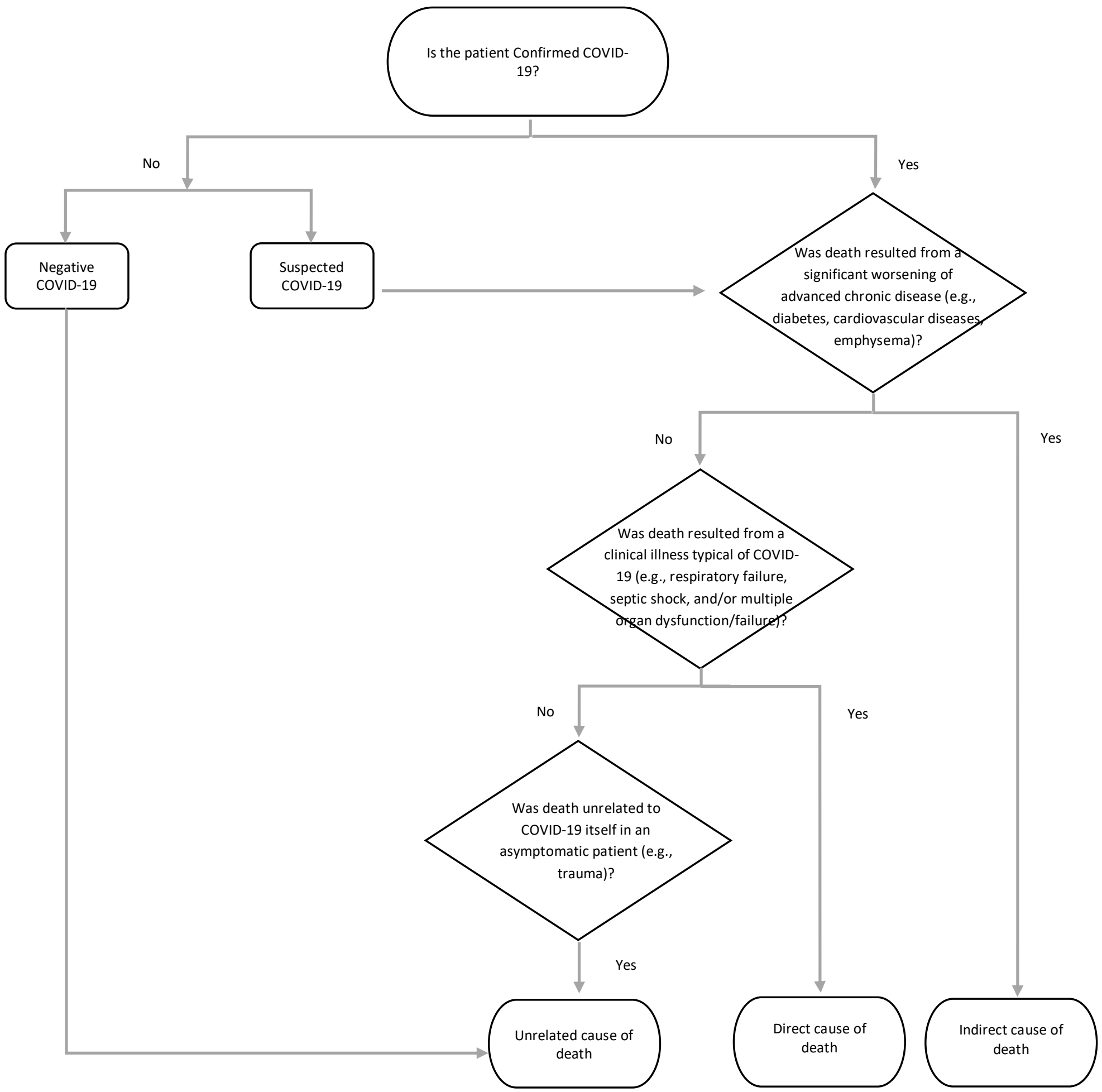


Figure 2: cCFR G20 comparison

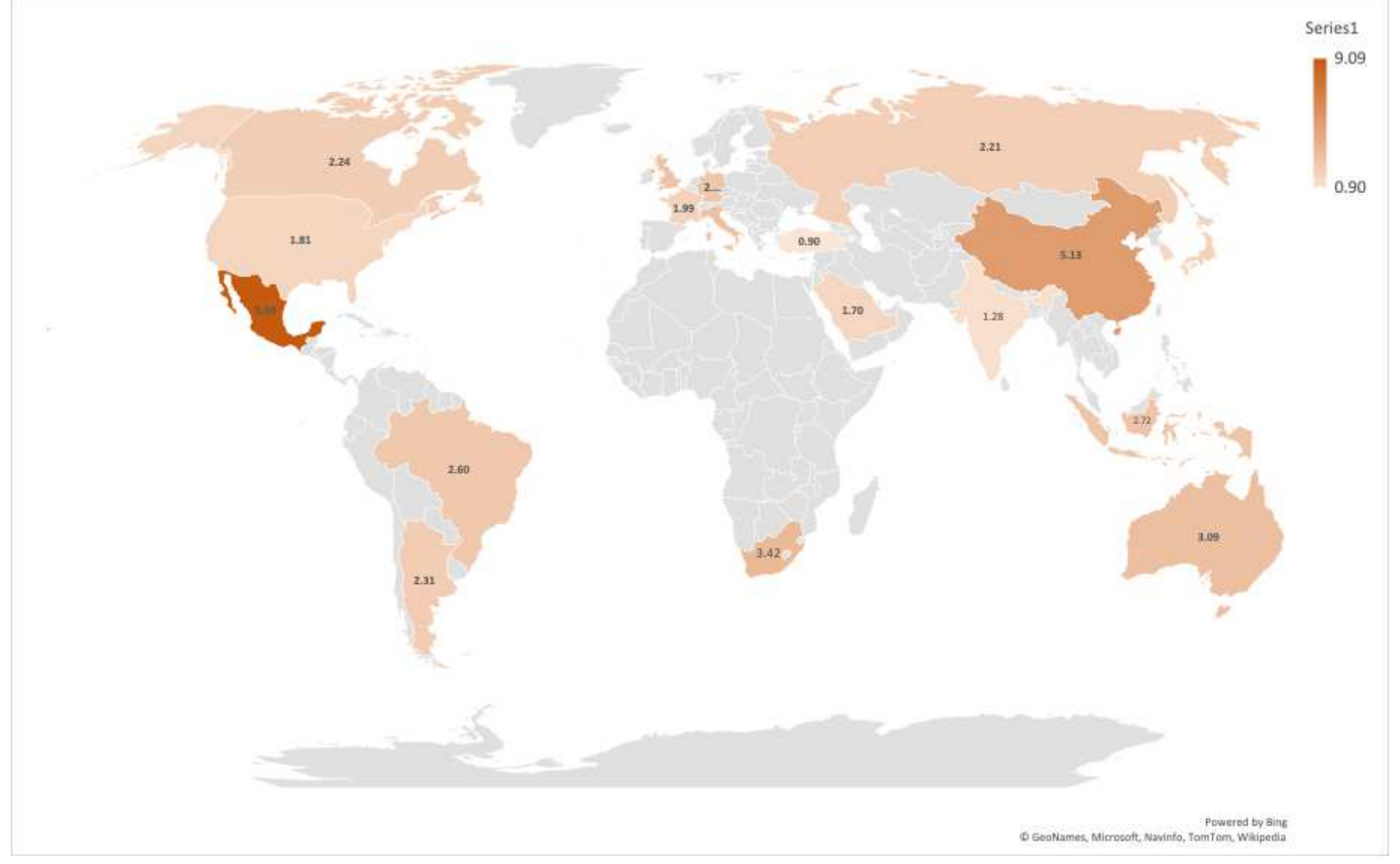




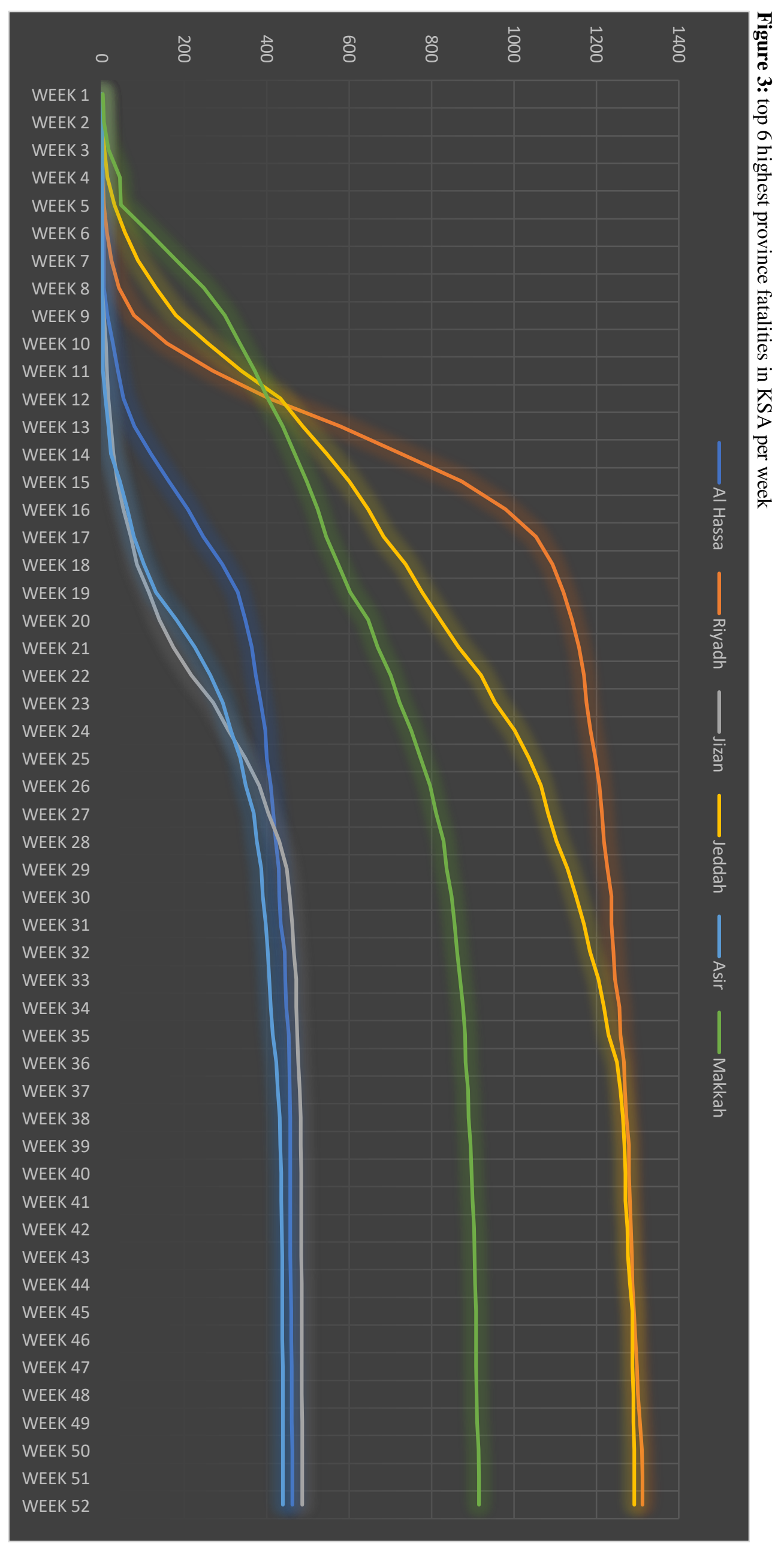




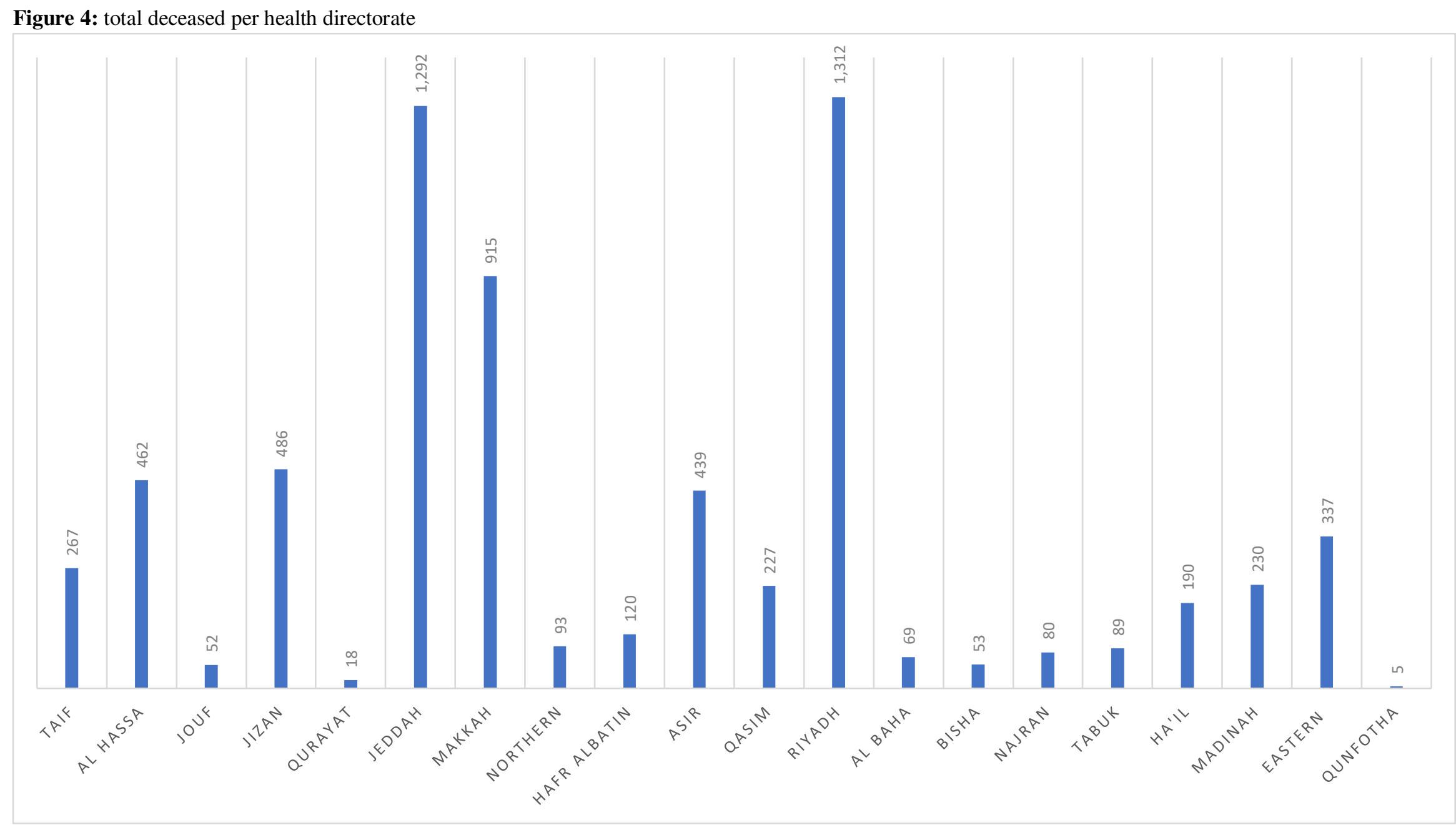




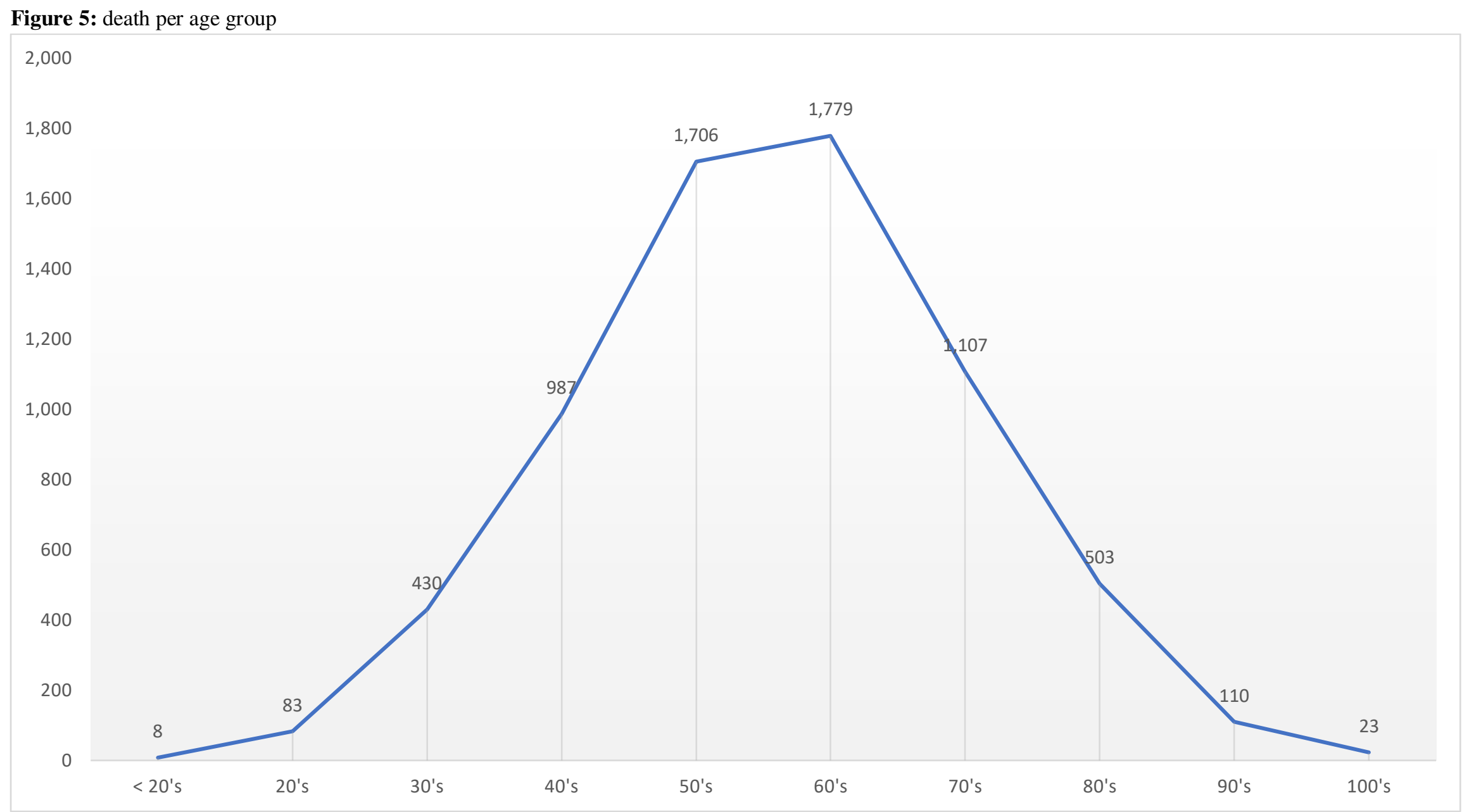




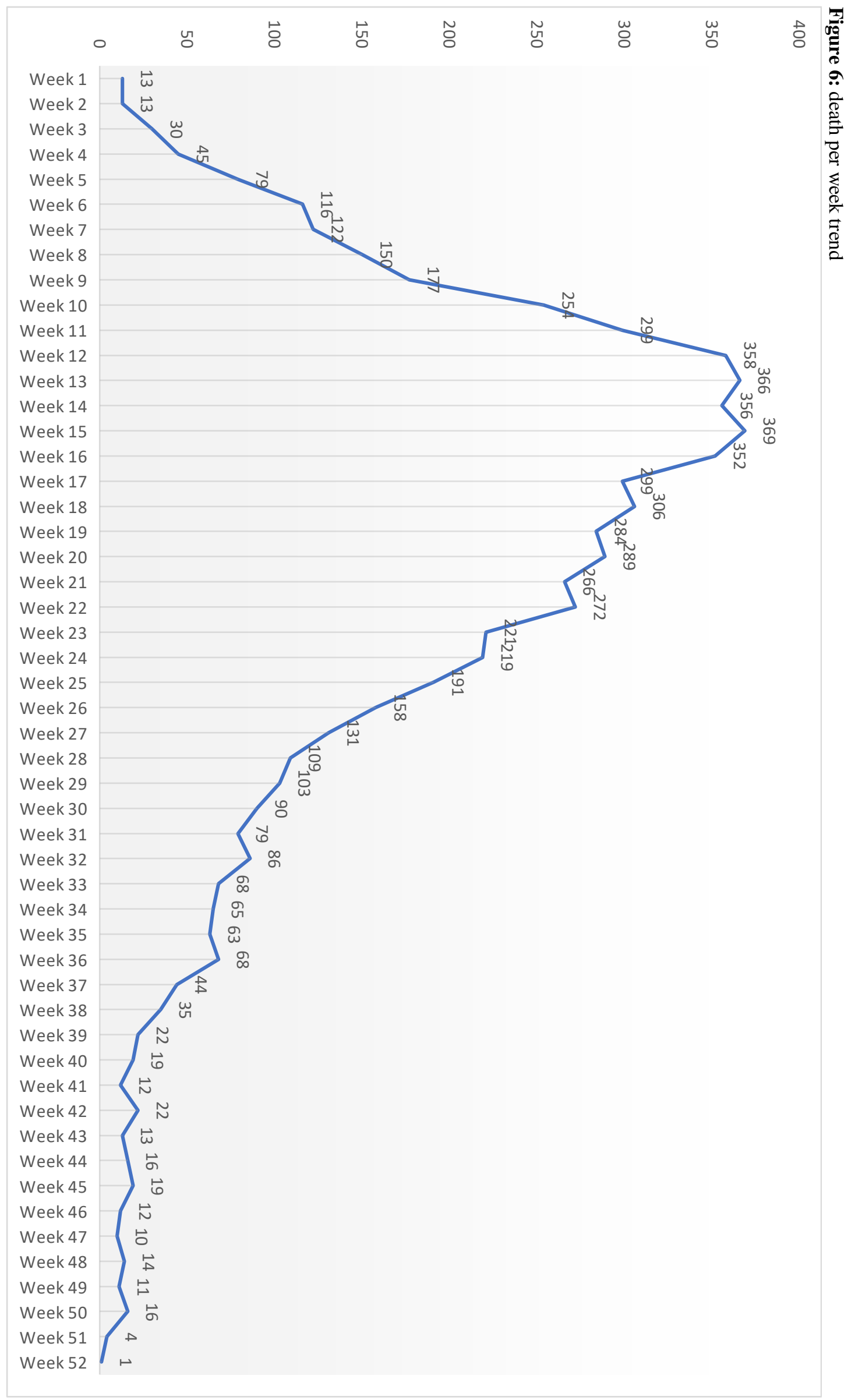


Figure 7: forest plots of the co-morbidities and association with COVID-19 mortality represented by odds ratios and confidence intervals

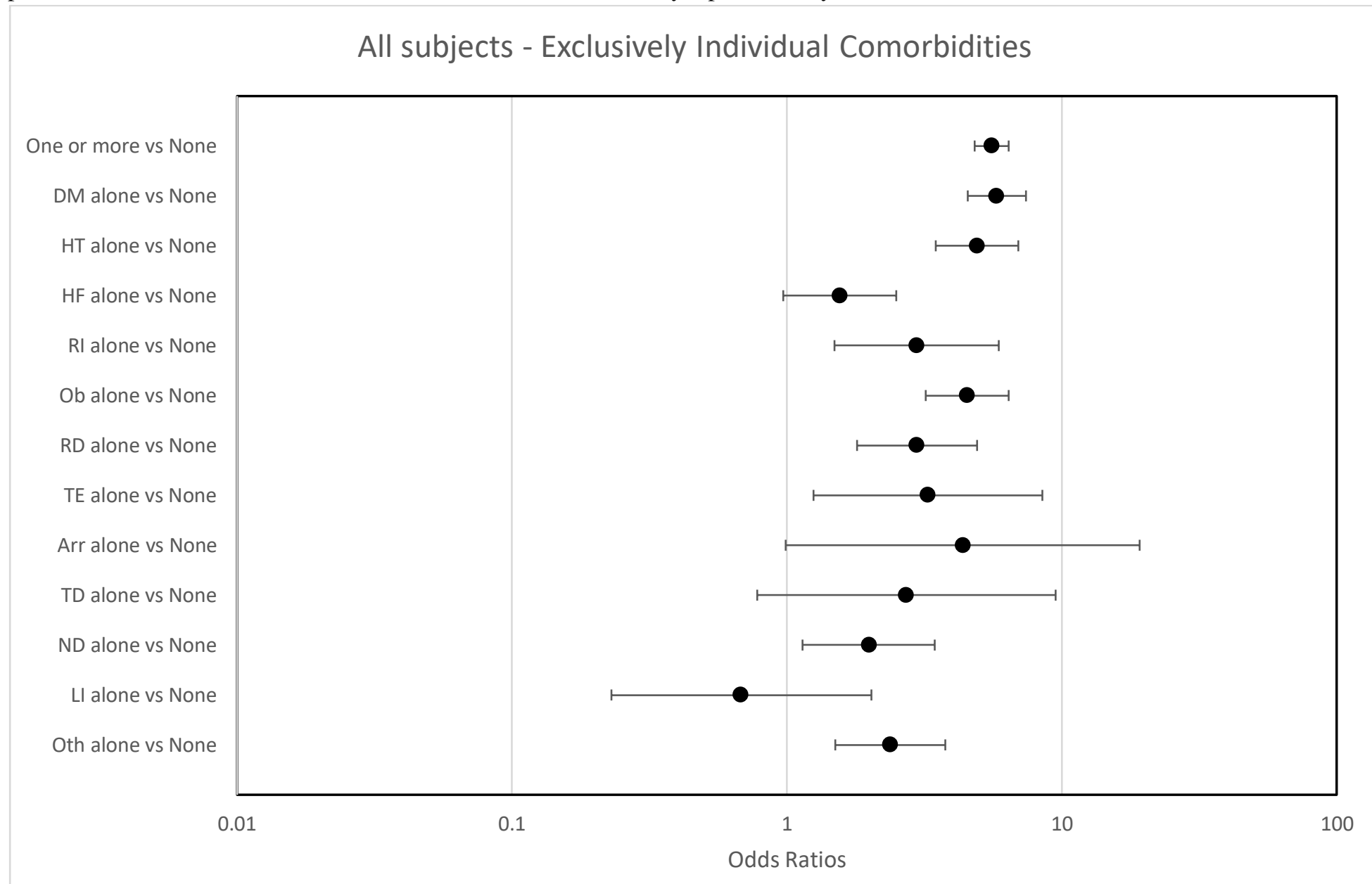

* - diabetes (DM), hypertension (HT), heart failure (HF), renal impairment (RI), obesity (Ob), respiratory disorder (RD), thromboembolic disorder (TE), arrhythmia (Arr), thyroid dysfunction (TD), neurological disorder (ND), liver impairment (LI), some other comorbidity(ies) (Oth) 
Figure 8: forest plots of multiple co-morbidities and association with COVID-19 mortality represented by odds ratios and confidence intervals All subjects - Comorbidities together

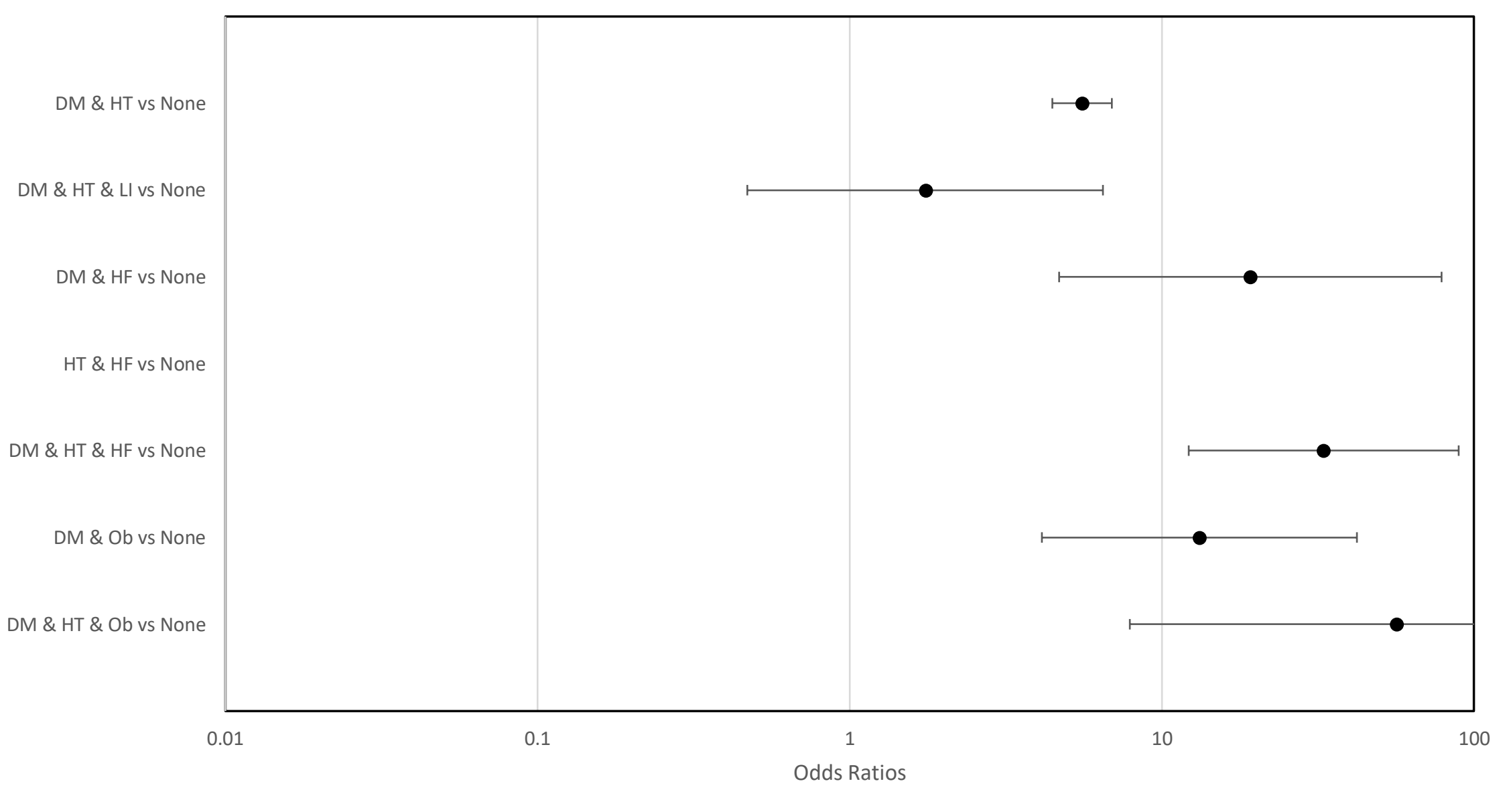




\section{Supplementary Files}

This is a list of supplementary files associated with this preprint. Click to download.

- Supplementaryfile.pdf 